\title{
Practical Issues in Catalytic and Hydrothermal Biomass Conversion: Concentration Effects on Reaction Pathways
}

\author{
Zbig W. Srokol · Gadi Rothenberg
}

Published online: 29 June 2010

(c) The Author(s) 2010. This article is published with open access at Springerlink.com

\begin{abstract}
Converting biomass to biofuels and chemicals calls for practical and simple processes, since it must compete economically with both burning and anaerobic bacterial digestion. Here we employ concentrated glucose solutions as a biomass model compound, using a pressure-controlled batch reactor setup for hydrothermal and catalytic upgrading. We examine the hydrothermal, acidcatalysed and base-catalysed reactions of concentrated glucose giving gases, tar (biofuels), and char products, and show that working at practical (i.e., high) feed concentrations has a strong effect on the reaction pathways.
\end{abstract}

Keywords Biomass - Hydrothermal - Conversion · Catalysis

\section{Introduction}

Promising routes to energy from biomass include gasification [1], fast pyrolysis [2] and hydrothermal upgrading (HTU) [3]. The latter gives an organic crude oil (biocrude) that has a heating value approaching that of fossil

Z. W. Srokol $(\bowtie) \cdot$ G. Rothenberg

Yellow Diesel B.V., P.O. Box 2535, 1000 CM Amsterdam,

The Netherlands

e-mail: z.w.srokol@yellowdiesel.com

G. Rothenberg

Van't Hoff Institute for Molecular Sciences, University of Amsterdam, Nieuwe Achtergracht 166, 1018WV Amsterdam,

The Netherlands fuels [4]. During HTU, the oxygen content of the biomass feed is reduced from ca. 40 to $10-15 \%$. The oxygen ends up in $\mathrm{CO}_{2}$ and water. The main organic components of biomass are cellulose, hemicelluloses and lignin. During the initial HTU stage, cellobiose and other polysaccharides hydrolyze to glucose. Thus, glucose is a reasonably good model compound for studying HTU pathways (there are limitations to the glucose model, e.g. the lignin present in biomass).

Several groups studied the decomposition of glucose in water under HTU conditions [5-10]. Previously, one of us published a study on the reactions of dilute glucose feeds as biomass model compounds [11]. Water-soluble products were obtained under these conditions. These were explained by both acid- and base-catalysed reactions as a result of the relatively high value of $K_{\mathrm{d}}$ under subcritical conditions. The main products from this diluted glucose feed were glyceraldehydes and 5-hydroxymethylfurfural (HMF). Surprisingly, no $\mathrm{CO}_{2}$ or tar products were detected (we define tar as tetrahydrofuran-soluble and char as THF-insoluble products). However, Kruse et al. reported that lignin-free baby food, when treated at 310 $410{ }^{\circ} \mathrm{C}$ and $30-50 \mathrm{MPa}$, for $15 \mathrm{~min}$ yielded large amounts of $\mathrm{CO}_{2}$ [12], while Minoa et al. demonstrated that cellulose is initially converted to water-soluble low molecular weight compounds, that subsequently form gases, tar (biofuels) and char [13]. This suggested to us that condensation reactions of these initial reaction products, and their respective concentrations, play an important role in biofuels formation. Here, we employ concentrated glucose solutions as a biomass model compound. We examine the hydrothermal, acid-catalysed and base-catalysed reactions of concentrated glucose and show that working at high feed concentrations strongly affects the reaction pathways. 


\section{Experimental}

\subsection{Materials and Instrumentation}

Gel Permeation Chromatography (GPC) analyses were performed with two columns in series packed with $\mathrm{SSTYRAGEL}$ with pore size of 100 and $500 \AA$, respectively. A refractive index (RI) (Shodex SE-51) detector was used. ${ }^{1} \mathrm{H}$ NMR spectra were measured on a Varian Unity INOVA-300 spectrometer $(300 \mathrm{MHz}, t$-BuOH/D $2 \mathrm{O}$ internal standard, $\delta=120 \mathrm{ppm}$. Mass spectral analyses were done on LC Quattro $\mathrm{ESP}^{+}$spectrometer. Total Organic Carbon (TOC) analyses were performed using a Shimadzu 5050A instrument. Unless noted otherwise, chemicals were obtained from Aldrich $(>99 \%)$ and used without further purification. Water was demineralized (conductivity $18.2 \mathrm{~m} \Omega \mathrm{cm}$ ). The HTU biocrude distillate was a gift sample from the Dutch company Biofuels B.V. HPLC analyses were carried out with a Millipore-Waters 590 pump and Phenomena Raze organic acid column at $60{ }^{\circ} \mathrm{C}$, (THF internal standard). Hydrothermal reactions of the highly concentrated solutions of the model compounds were performed using a batch reactor set-up (Fig. 6), constructed from 316 stainless steel. The reactor was filled by means of an HPLC pump. A back pressure regulator controlled the pressure during the reaction. After heating to the desired temperature, the reactor was kept at this temperature for a period $0-15 \mathrm{~min}$. To avoid overheating, the reactor was isolated by water-cooling jackets on both sides, as well as using a stream of a cold air. The amounts of gases were measured by gas burette connected to the reactor outlet.

\subsection{Adapting the Reactor System for High-Concentration Feeds}

Using diluted solutions $(50 \mathrm{mM})$ in a continuous flow reactor at $340{ }^{\circ} \mathrm{C}$ and 280 bar for 25-200 s gave negligible amounts of tar and char. However, attempting similar reactions with high feed concentrations in this setup failed due to blocking of the reactor by the tar and char formed under those conditions. Therefore, we performed the high-concentration reactions in a different system. Quick tests were done in a $6 \mathrm{ml}$ batch reactor (Fig. 1, left). Long-term studies were done in a $150 \mathrm{ml}$ reactor (Fig. 1, right). Control HTU experiments with both setups using diluted glucose solutions (50 $\mathrm{mM}$ ) gave similar results as obtained previously with the continuous flow reactor [11]. The disadvantage of the larger set-up was that the heat-up and cool-down times are long ( $\sim 20 \mathrm{~min}$ ). Therefore, only relatively slow reactions could be studied. With the smaller reactor, heat-up and cool-down times were only about $1.5 \mathrm{~min}$ and $10 \mathrm{~s}$, respectively.

\section{Results and Discussion}

In a typical reaction (Eq. 1), a concentrated glucose feed $(\mathbf{1}, 500 \mathrm{mM}, 90 \mathrm{~g} / \mathrm{L})$ was reacted in an autoclave at $340{ }^{\circ} \mathrm{C}$ and 17.5 Map. The glucose decomposed to several small molecules, chiefly acids. These lowered the $\mathrm{pH}$ down to
Fig. 1 Schematics of the small (left) and large (right) batch HTU reactors

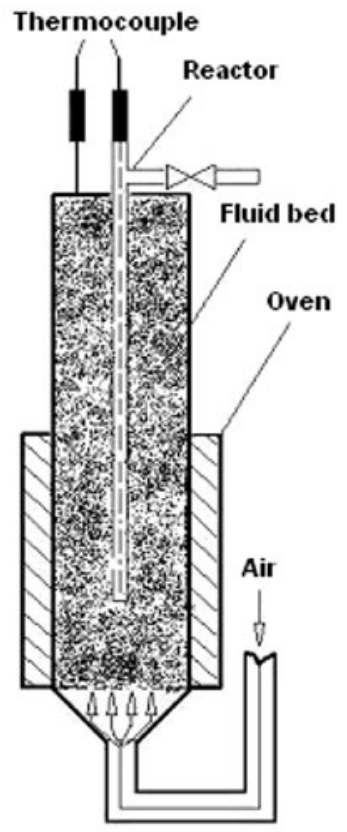


2.3-2.8, catalyzing a host of reactions, including aldol condensations, eliminations, and $\mathrm{C}-\mathrm{C}$ bond cleavages. The main products were glyceraldehydes $\mathbf{2}$, 5-hydroxymethylfurfural 3, 1,2,4-benzenetriol $\mathbf{4}$, acetic acid $\mathbf{5}$, acetone $\mathbf{6}$, formic acid $\mathbf{7}$, and furfural $\mathbf{8}$. Note that although the main liquid-phase products did not change with increased feed concentration, the reaction at high concentrations (250$500 \mathrm{mM}$ ) afforded, in addition to water-soluble products, substantial amounts of tar, char, and gases. amounts of tar, char, and gases obtained in reactions with 250 and $500 \mathrm{mM}$ glucose were considerable. Moreover, upon increase of the glucose concentration the amounts increased.

\subsection{The Water Phase and $\mathrm{pH}$ Effects}

The $\mathrm{pH}$ of the water layers measured after the reaction varied from 2.3 to 2.8. Upon increase of the initial glucose

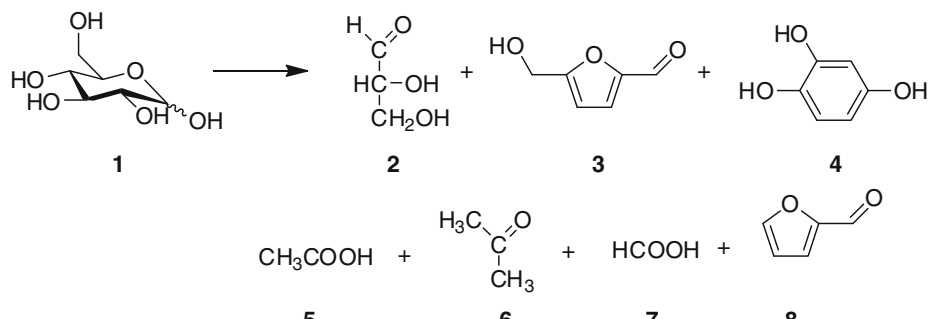

Figure 2 shows the distribution profiles for tar, char and gas products for the various feed concentrations. The concentration, the $\mathrm{pH}$ of the products mixture decreased. Importantly, the product distribution between the low
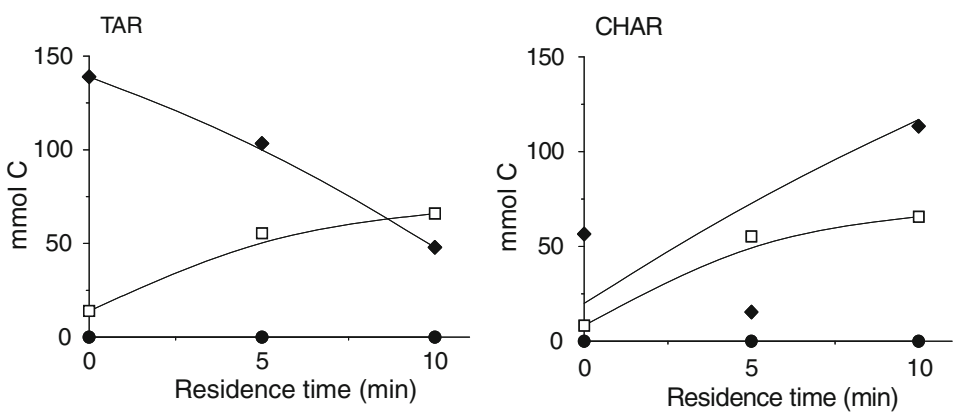

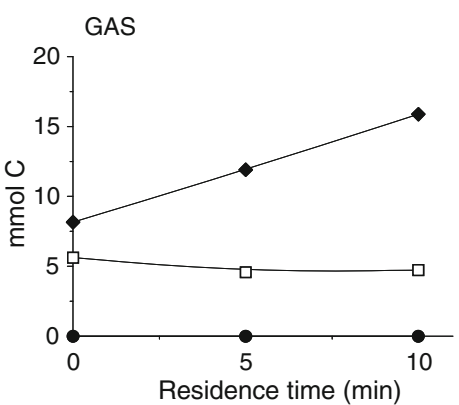

Fig. 2 Amount of tar, char, and gases obtained during the hydrothermal reactions of $150 \mathrm{~mL}$ of an aqueous solution of glucose (filled circle $50 \mathrm{mM}$, open square $250 \mathrm{mM}$, filled diamond $500 \mathrm{mM}$, corresponding to an intake of $45,225,450 \mathrm{mmol} \mathrm{C}$ ), reaction temperature $340{ }^{\circ} \mathrm{C}$, pressure $17.5 \mathrm{MPa}$. Residence times were calculated after reaching the desired temperature

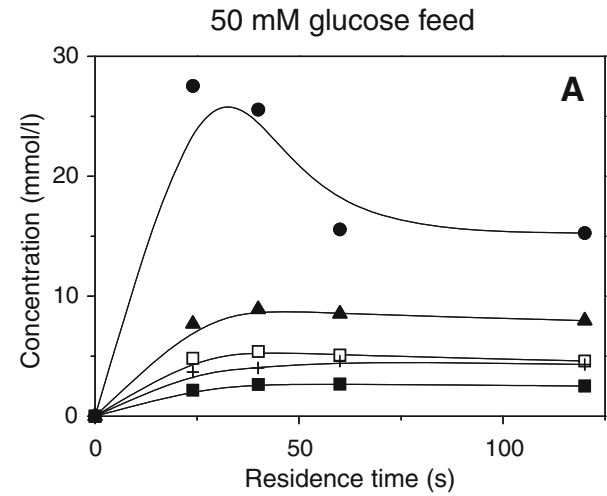

Fig. 3 Distribution of the main products in the water phase during the hydrothermal reaction of glucose, (a) $50 \mathrm{mM}$ solution in continuous reactor with $25-120 \mathrm{~s}$ residence time at $340{ }^{\circ} \mathrm{C}$ and $27.5 \mathrm{MPa}$, (b) $150 \mathrm{~mL}$ of a $500 \mathrm{mM}$ solution in batch reactor at $340{ }^{\circ} \mathrm{C}$ and $17.5 \mathrm{MPa}$ (lower pressure for safety reason), filled circle
$500 \mathrm{mM}$ glucose feed

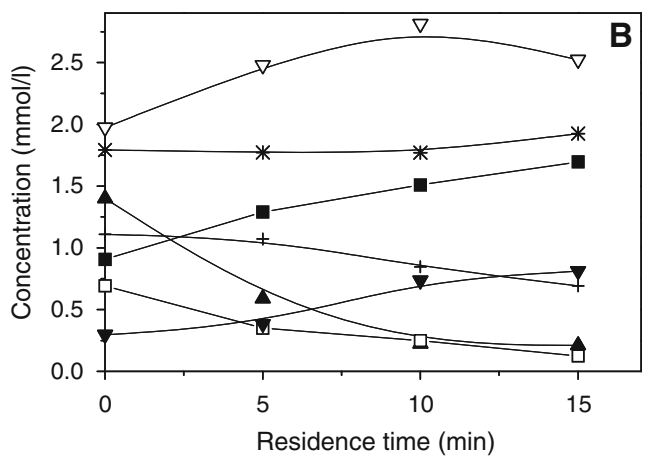

glycolaldehyde, filled triangle 5-hydroxymethylfurfural, filled square trihydroxybenzene, asterisk acetic acid, filled inverted triangle acetone, open triangle dihydroxyacetone, plus formic acid, open inverted triangle levulinic acid, open square 2 -furfural 
concentration and high concentration feeds differs significantly (Fig. 3). Note that the concentrations in the water layer of the $500 \mathrm{mM}$ reaction are an order of magnitude lower. Since only low-molecular-weight compounds were detected, we conclude that the initial products formed from glucose reacted further, giving water-insoluble compounds (tar and char) and gases.

A striking difference between the two reactions is that glycolaldehyde, which is the major initial product of a $50 \mathrm{mM}$ solution, decreases rapidly during the reaction of the $500 \mathrm{mM}$ solution. One explanation is that glycolaldehyde is rapidly converted into other products during hydrothermal reactions at higher concentrations. In the water layer, no products were found that could be formed from glycolaldehyde via fragmentation or dehydratation. We envisage that the initially formed glycolaldehyde is involved in bimolecular reactions leading to high-molecular weight compounds that end up in the tar or char fractions. The major product using the $500 \mathrm{mM}$ glucose feed was levulinic acid. Notably, this was not observed in reactions with the $50 \mathrm{mM}$ solution, even at prolonged reaction times. Formation of levulinic acid from glucose requires splitting off of water and either $\mathrm{CO}$ or formic acid. Glucose easily equilibrates with fructose under the HTU conditions. Dehydration of fructose can give hydroxymethylfurfural, which can eliminate $\mathrm{CO}$, giving levulinic acid [14]. Scheme 1 shows a possible acid-catalysed pathway (note that a control reaction in the presence of $6 \mathrm{mM} \mathrm{HCl}$ did yield levulinic acid when starting from a $50 \mathrm{mM}$ glucose feed). Apparently, the slightly lower $\mathrm{pH}$ of the reaction mixture starting from the $500 \mathrm{mM}$ glucose feed suffices to catalyse the formation of levulinic acid. The initial concentrations of formic acid are rather high, explaining the decrease in $\mathrm{pH}$.

Hydroxymethylfurfural (HMF) was the second initial main product observed in the hydrothermal treatment of
Table 1 Relative amounts of water layer products from hydrothermal treatment of glucose and of a wood stick

\begin{tabular}{lll}
\hline Compounds & Glucose $^{\mathrm{a}}$ & Wood stick $^{\mathrm{b}}$ \\
\hline HMF & 1 & 1 \\
1,2,4-trihydroxybenzene & 2.22 & 0.96 \\
Furfural & 0.57 & 0.59 \\
Acetic acid & 2.56 & 3.80 \\
Formic acid & 1.81 & 1.24 \\
Acetone & 0.64 & 0.33 \\
\hline
\end{tabular}

a $500 \mathrm{mM}, 340{ }^{\circ} \mathrm{C}, 17.5 \mathrm{MPa}$

b Sample obtained from HTU wood stick treatment $400{ }^{\circ} \mathrm{C}$ in a sealed capillary

$50 \mathrm{mM}$ glucose. This product was also present in the water layers of the $500 \mathrm{mM}$ glucose, but at relatively low concentrations. Conversion of HMF into levulinic acid may account for this. Another route is the previously described conversion into 1,2,4-benzenetriol [8]. We also analyzed by ${ }^{1} \mathrm{H}$ NMR a sample obtained from Knezevic et al., of a water layer obtained by the hydrothermal treatment of a wood stick. Table 1 compares the composition of this water layer with that obtained from our HTU of glucose. The compositions of these water layers are very similar, supporting our hypothesis that mainly products from hydrothermal reactions of cellulose end up in the water layer.

\subsection{The Tar and Char Phases}

The tar and char phases from the reactions in the $150-\mathrm{mL}$ reactor were analysed by Gel Permeation Chromatography (GPC), ${ }^{1} \mathrm{H}$ NMR and ${ }^{13} \mathrm{C}$ NMR. GPC analysis showed that the molecular weight distribution of the tar was almost independent of the residence time and of the temperature.

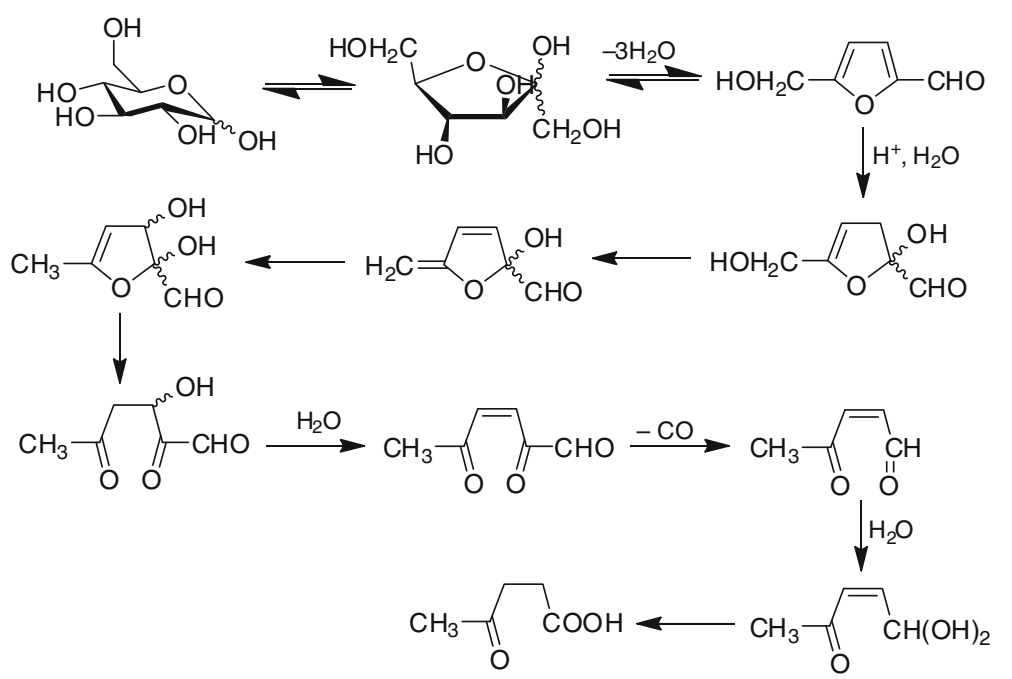

Scheme 1 Suggested pathway for the formation of levulinic acid during the hydrothermal treatment of $500 \mathrm{mM}$ D-glucose in water 
Fig. 4 (a) ${ }^{1} \mathrm{H}$ NMR spectrum and (b) ${ }^{13} \mathrm{C}$ NMR spectrum of a solution in THF- $\mathrm{d}_{8}$ of the tar fraction obtained from hydrothermal treatment of a $500 \mathrm{mM}$ solution of D-glucose in reactor 2 at $340{ }^{\circ} \mathrm{C}$ and 17.5 MPa. The asterisks indicate resonances due to $\left(\mathrm{THF}-\mathrm{d}_{8}\right)$
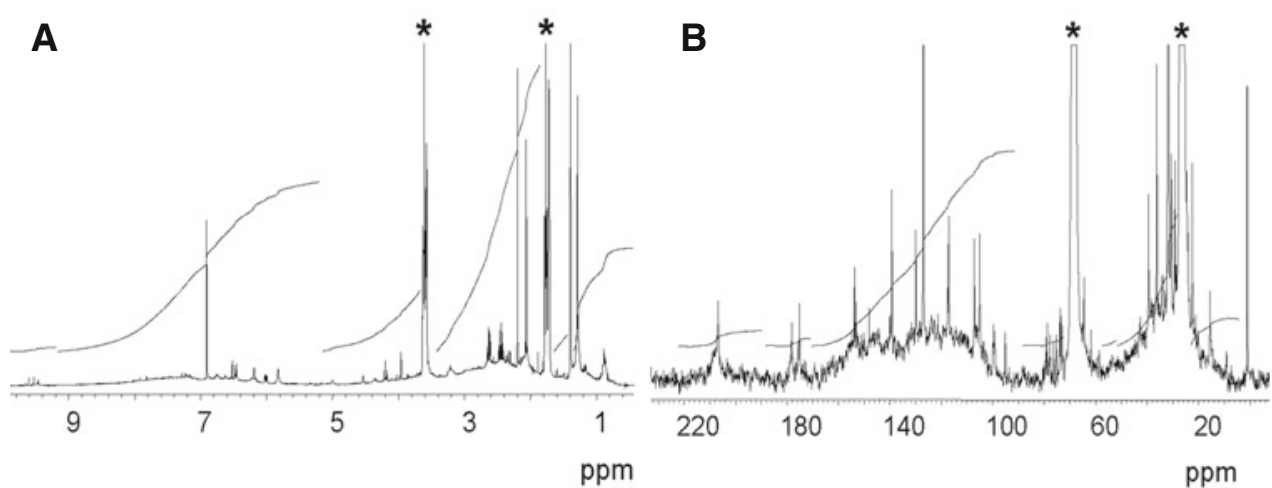

\begin{tabular}{|c|c|c|}
\hline Chemical shift (ppm) & $\begin{array}{l}\text { Integral } \\
\text { (\% of total) }\end{array}$ & Assignment \\
\hline \multicolumn{3}{|l|}{${ }^{13} \mathrm{C}$} \\
\hline $0-52$ & 42 & aliphatic Cs \\
\hline $52-85$ & 2 & sugar and polyol Cs \\
\hline $90-168$ & 50 & olefinic and aromatic Cs \\
\hline 168-185 & 2 & ester carbonyl and carboxyl Cs \\
\hline$>185$ & 4 & aldehyde and ketone carbonyl Cs \\
\hline \multicolumn{3}{|l|}{${ }^{1} \mathrm{H}$} \\
\hline $0-5.2$ & 73 & aliphatic Hs \\
\hline $5.2-9$ & 26 & olefinic and aromatic Hs \\
\hline $9-11$ & 1 & aldehyde Hs \\
\hline
\end{tabular}

The quantitative ${ }^{1} \mathrm{H}$ and ${ }^{13} \mathrm{C}$ NMR spectra of these fractions confirmed that their composition is independent of reaction time and temperature. Figure 4 shows typical NMR spectra. We see mainly very broad unresolved resonances, suggesting that the tar consists predominantly of complex high molecular weight compounds. The ${ }^{13} \mathrm{C}$ NMR spectra also showed a number of narrow resonances, ascribed to low molecular weight compounds. However, the total intensity of those resonances is negligible in

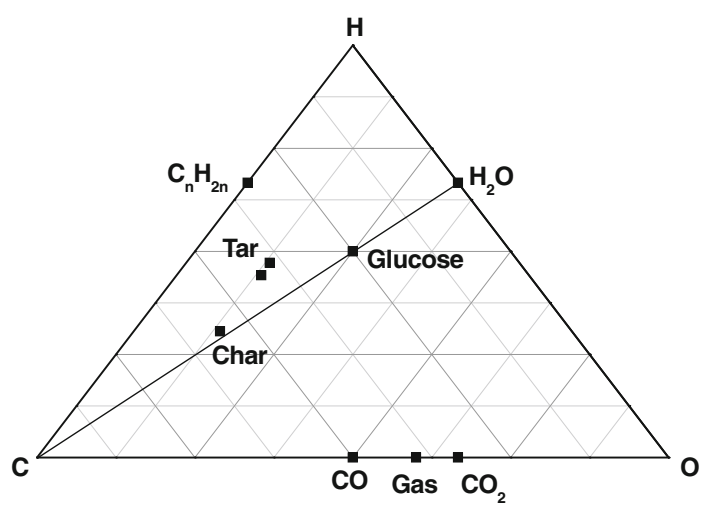

Fig. 5 Elemental composition diagram (mole \%) of the char fraction comparison to that of the broad resonances. These results agree with the GPC analysis. The low integral of the region between 52 and $85 \mathrm{ppm}$ in the ${ }^{13} \mathrm{C}$ NMR spectra indicates that polyol and sugars are almost completely converted into less oxygenated compounds. The low intensity of aldehyde peaks (9-11 ppm) in the ${ }^{1} \mathrm{H}$ NMR spectrum shows that the aldehydes that were initially detected in the hydrothermal reaction of diluted D-glucose samples are completely converted in other products when using the concentrated feed.

The tar from the $500 \mathrm{mM}$ glucose feed reaction was distilled under vacuum. Only a small fraction $(1.0 \mathrm{wt} \%)$, with a boiling point of $40^{\circ} \mathrm{C} / 0.1 \mathrm{~mm} \mathrm{Hg}$ was obtained. GC-MS analysis showed that this fraction consisted of compounds, several of which stem from phenol derivatives and from HMF. The elemental analyses of the char and tar fraction of the reaction of a $500 \mathrm{mM}$ solution show that char contains $72.88 \mathrm{wt} \% \mathrm{C}, 3.34 \mathrm{wt} \% \mathrm{H}$, and $23.78 \mathrm{wt} \%$ O. Tar obtained after $5 \mathrm{~min}$ contains $63.67 \mathrm{wt} \% \mathrm{C}, 6.34$ wt $\% \mathrm{H}, 28.44 \mathrm{wt} \% \mathrm{O}$, and tar obtained after $20 \mathrm{~min}$ contains $64.84 \mathrm{wt} \%$ C, $5.64 \mathrm{wt} \% \mathrm{H}, 27.24 \mathrm{wt} \%$ O. In Fig. 5 the composition is compared with that of tar and of the starting compound D-glucose. Since glucose, $\mathrm{H}_{2} \mathrm{O}$ and char are almost on a straight line, we conclude that most of the char 


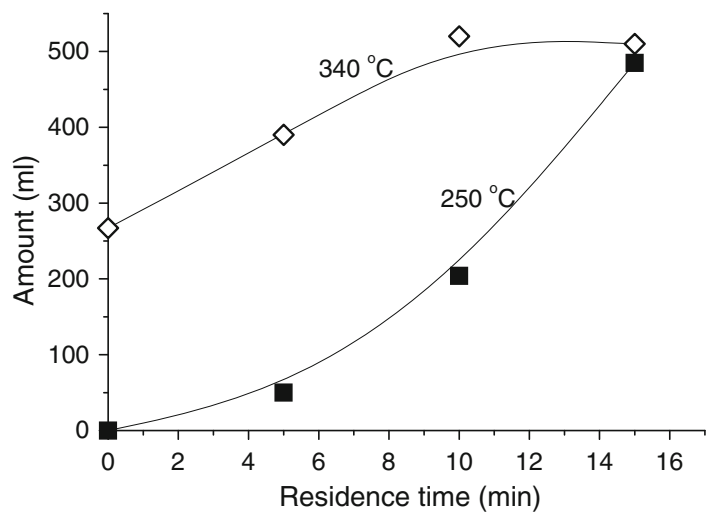

Fig. 6 Amounts of gases (measured at 1 atm and $25{ }^{\circ} \mathrm{C}$ ) produced during the hydrothermal reaction of $500 \mathrm{mM}$ D-glucose in reactor 2 at $250{ }^{\circ} \mathrm{C}, 340{ }^{\circ} \mathrm{C}$ and $17.5 \mathrm{MPa}$ as a function of the reaction time. Gas concentrations were determined by GC analysis

is formed by dehydration reactions. The location of the points for tar and gas on different sides of this line suggest that these are formed by a disproportionation process.

\subsection{The Gas Phase}

The formation of gases parallels that of the tar. The main gases formed are $\mathrm{CO}, \mathrm{CO}_{2}, \mathrm{H}_{2}$, and propene. The amount formed increases with the residence time (see Fig. 6). For example, after $10 \mathrm{~min}$ the gas product mixture contained $\mathrm{CO}, \mathrm{CO}_{2}$, ethene and propene in a molar ratio: 1:0.9:0.001:0.009. The amount of $\mathrm{H}_{2}$ was about equal to that of $\mathrm{CO}$. Therefore, the formation of $\mathrm{CO}_{2}$ and hydrogen can be ascribed to the water gas shift reaction. Large amounts of $\mathrm{CO}$ form during the hydrothermal treatment of glucose, indicating that decarbonylation is an important pathway. Carboxylic acids can decarbonylate under highly acidic conditions via formation of carbenium ions that subsequently deprotonate to an alkenes or hydrate to alcohols [15]. Most likely propene also forms in this way from butanoic acid. The presence of propene in the reaction medium, the occurrence of decarbonylations, and the acidity of the reaction medium ( $\mathrm{pH} \mathrm{2-3)} \mathrm{all} \mathrm{suggest} \mathrm{that}$ carbenium ions play a role in the later stages of the HTU process. Consequently, polymerisation reactions via carbenium pathways may account for the high molecular weight compounds observed in the tar.

\section{Conclusions}

The initial feed concentration is an important parameter for reducing the oxygen content of biomass by HTU. Only at higher concentrations $(>250 \mathrm{mM})$, the model compound glucose forms gases and tar with a high $\mathrm{C} / \mathrm{O}$ ratio. The reaction pathways resemble those proposed for the alkaline degradation of sugars. Initially, D-glucose degrades to a mixture of aldehydes as a result of base-catalysed isomersations, retro-aldol reactions, $\beta$-eliminations, $\alpha$-dicarbonyl cleavages, and aldol condensations [16]. These then form carboxylic acids via irreversible base-catalysed benzylic rearrangements and $\alpha$-dicarbonyl cleavages. Next to these base-catalysed reactions, acid-catalysed reactions and alkylations occur. Initially, dehydration to HMF-type compounds is an important pathway. The importance of the acid-catalysed reactions increases with time, as formic and acetic acid form. The carboxylic acids decarbonylate to olefins, that subsequently may polymerize under the acidic reaction conditions. In the final tar fraction, only $4 \%$ of the $\mathrm{C}$-atoms is in a carbonyl function.

Acknowledgements We thank E. Wurtz and R. Sloter for help with reactor building, Dr. F. Goudriaan and Dr. L. Petrus for discussions, J. Knoll for performing the TOC analyses, A. van Estrik and K. Djanashvili for performing NMR analyses and D. Knezevic (University of Twente) for providing the wood stick HTU reaction sample.

Open Access This article is distributed under the terms of the Creative Commons Attribution Noncommercial License which permits any noncommercial use, distribution, and reproduction in any medium, provided the original author(s) and source are credited.

\section{References}

1. Matsumura Y, Minowa T, Potic B, Kersten SRA, Prins W, van Swaaij WPM, van de Beld B, Elliott CD, Neuenschwander GG, Kruse A, Jr Antal MJ (2005) Biomass Bioenergy 29:269

2. Bridgwater AV, Czernik S, Piskorz J (2000) An overview of fast pyrolysis. Progress in thermochemical biomass conversion, [Conference], 5th, Tyrol, Austria, Sept pp 17-22

3. Goudriaan F, Peferoen DGR (1990) Chem Eng Sci 45:2729

4. Goudriaan F, Naber JE, Zeevalkink JA (2004) NPT Procestechnologie 11:31

5. Sasaki M, Fang Z, Fukushima Y, Adschiri T, Arai K (2000) Ind Eng Chem Res 39:2883

6. Kabyemela BM, Takigawa M, Adschiri T, Malaluan RM, Arai K (1999) Ind Eng Chem Res 38:2888

7. Bobleter O, Bonn G (1983) Carbohydr Res 124:185

8. Luijkx GCA, van Rantwijk F, van Bekkum H, Antal MJ (1995) Carbohydr Res 272:191

9. Kabyemela BM, Adschiri T, Malaluan RM, Arai K (1997) Ind Eng Chem Res 36:1552

10. Kallury RKMR, Ambidge C, Tidwell TT, Boocock DGB, Agblevor FA, Stewart DJ (1986) Carbohydr Res 158:253

11. Srokol Z, Bouche A-G, van Estrik A, Strik RCJ, Maschmeyer T, Peters JA (2004) Carbohydr Res 339:1717

12. Kruse A, Gawlik A (2003) Ind Eng Chem 42:267

13. Minowa T, Fang Z, Ogi T, Varhegyi G (1998) J Chem Eng Jpn $31: 131$

14. Horvat J, Klaic B, Metelko B, Sunijc V (1985) Tetrahedron Lett 26:2111

15. Deno NC, Pittman CU Jr, Wisotsky MJ (1964) J Am Chem Soc $86: 4370$

16. De Bruijn JM (1986) Monosaccharidies in alkaline medium: isomerisation, degradation, oligomerization. Ph.D. Thesis, Delft University of Technology 